\title{
Disruption of imprinting in cloned mouse fetuses from embryonic stem cells
}

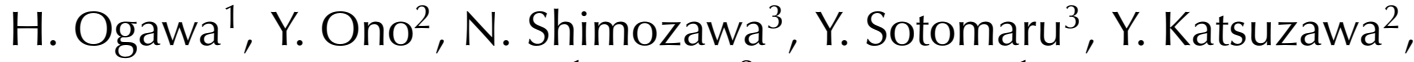 \\ H. Hiura ${ }^{1}$, M. Ito ${ }^{3}$ and T. Kono ${ }^{1 *}$ \\ ${ }^{1}$ Department of BioScience, Tokyo University of Agriculture, 1-1-1 Sakuragaoka, Setagaya-ku, \\ Tokyo 156-8502, Japan; ${ }^{2}$ Department of Animal Science, Tokyo University of Agriculture, \\ 1737 Funako, Atsugi-shi, Kanagawa 243-0034, Japan; and ${ }^{3}$ Central Institute for Experimental Animals, \\ 1430 Nogawa, Miyamae-ku, Kawasaki-shi, Kanagawa 216-0001, Japan
}

\begin{abstract}
Cloned mice typically display abnormal development, such as overgrowth of fetuses and placentae. Quantitative expression analysis of eight imprinted genes $(H 19$, Igf2, Igf2r, Air, Peg1/Mest, Peg3, Nuronatin (Nnat) and Ndn) and an alternate transcript of $\boldsymbol{I g f} \mathbf{2}(\boldsymbol{P O})$ in embryonic stem cloned fetuses and placentae at days 9.5, 12.5 and $\mathbf{1 7 . 5}$ after mating was carried out by real time PCR to investigate whether epigenetic modification of imprinted genes is responsible for overgrowth of the fetus and placental hypertrophy. In addition, the methylation pattern through the bisulphite sequencing method in differentially methylated regions of $\mathrm{H} 19$ and Igf2r was examined in day 9.5 fetuses and placentae. The results showed clearly that the expression of $\mathrm{H19}$ gene decreased in cloned fetuses at days $\mathbf{1 2 . 5}$
\end{abstract}

and $\mathbf{1 7 . 5}$ after mating and in placentae at day $\mathbf{1 7 . 5}$ after mating, and Igf2 was also repressed in fetuses at days $\mathbf{9 . 5}$ and $\mathbf{1 2 . 5}$ after mating and in placentae at day $\mathbf{1 7 . 5}$ after mating. In contrast, the transcription of $P O$, which is a placental-specific transcript variant of Igf2, increased at more than four times the control in cloned placenta at day 12.5 after mating. Day 9.5 fetuses that have developed normally revealed only hypermethylated alleles in the $\mathrm{H19}$ differently methylated region (DMR), and both hyper- and hypomethylated alleles in the Igf2r DMR2. These results show that inappropriate reprogramming in some imprinted genes affects the development of cloned embryos, and that aberrant PO Igf2 transcription in particular may cause the overgrowth of cloned fetuses and placentae.

\section{Introduction}

Nuclear transfer technology has shown that transfer of somatic cells to enucleated unfertilized oocytes can result in successful development of cloned individuals in sheep (Wilmut et al., 1997), cattle (Kato et al., 1998), pigs (Onishi et al., 2000), goats (Baguisi et al., 1999), cats (Shin et al., 2002), rabbits (Chesne et al., 2002) and mice (Wakayama et al., 1998). However, the efficiency of somatic cell nuclear transfer in all species is still extremely low regardless of the origin of the cells. Studies so far have shown that cloned individuals often suffer from a wide range of severe malformations, such as overgrowth of the fetus and placenta (Ono et al., 2001a,b; Shimozawa et al., 2002a) and deficient immune systems (Renard et al., 1999; Wells et al., 1999; Ogonuki et al., 2002).

Embryonic stem (ES) cells that exhibit high pluripotency and that can differentiate into all tissues and organs of the fetus, but contribute only poorly to extraembryonic tissues in chimaeric mice, have been

${ }^{*}$ Correspondence

Email: tomohiro@nodai.ac.jp used as donor cells for nuclear transfer in attempts to improve cloning efficiency. Indeed, cloning from ES cells is more efficient than cloning from somatic cells (Jaenisch et al., 2002), but ES cloned mice are accompanied by the typical malformations seen in somatic cloned mice, such as placental hypertrophy and overgrowth of the fetus (Wakayama and Yanagimachi, 1999; Eggan et al., 2001; Ono et al., 2001a). It has been reported that placental hypertrophy is accompanied by abnormal formation of spongiotrophoblasts and the labyrinthine layers (Shimozawa et al., 2002a). These abnormal formations may interfere with utero-placental circulation and cause death before and after birth in cloned mice.

It has been argued that it is the irregular expression of imprinted and non-imprinted genes in cloned mice that leads to the abnormal development of the fetus and placenta (Humpherys et al., 2001; Rideout et al., 2001; Inoue et al., 2002). In these studies, aberrant expression in cloned tissues was particularly evident for four imprinted genes, H19, Igf2, Peg1/Mest and Meg1/Grb10 (Humpherys et al., 2001; Inoue et al., 2002). Proper epigenetic modifications, such as DNA methylation, by which imprinted gene expression is generally repressed, 
is necessary for the development of fertilized eggs into individuals. Otherwise, inappropriate reprogramming of epigenetic modifications after nuclear transfer may cause malformations in cloned embryos. The methylation status of DNA cytosine residues has been analysed (Humpherys et al., 2001; Kang et al., 2001a-c; Xue et al., 2002). Recent studies showed that inappropriate reprogramming of epigenetic modifications is evident, which may in turn affect mechanisms underlying the low cloning efficiency and the abnormal development (Rideout et al., 2001). For example, in cloned calves, both $\mathrm{X}$ chromosomes were active with a differently methylated region (DMR) in which the Xist gene was unmethylated (Xue et al., 2002). Expression of the H19 gene was depleted in an ES cloned mouse in which the DMR of the gene was hypermethylated (Humpherys et al., 2001). In contrast, parent specific expression of imprinted genes was maintained in somatic cloned mice (Inoue et al., 2002). However, to date, direct evidence that aberrant expressions of imprinted genes cause abnormal development in cloned embryos is lacking.

Shimozawa et al. (2002a) obtained an ES cell line that resulted in overgrowth of the fetus and severe placental hypertrophy. It was concluded that further insight into these typical occurrences in ES cloned embryos might be achieved by using this line to determine the expression of imprinted genes and the DNA methylation status of the DMR region during development after implantation. Therefore, the aim of the present study was to examine the expression of eight imprinted genes: H19, Igf2, Igf2r, Air, Peg1/Mest, Peg3, Nuronatin (Nnat) and Ndn, and an alternate transcript of lgf2 $(P O)$ in ES cloned fetuses at days $9.5,12.5$ and 17.5 after mating by quantitative expression analysis using real-time PCR. Moreover, methylation of $\mathrm{CpG}$ sites in DMRs of $\mathrm{H} 19$ and lgf2r genes was analysed, as these two genes are closely related to fetal development.

\section{Materials and Methods}

\section{Preparation of donor cells}

TT2 ES cells, which were derived from B6CBF1 male mice and had been targeted at the oviduct-specific glycoprotein gene, were used as donor cells. ES cells were cultured in knockout-Dulbecco's modified Eagle's medium (Gibco BRL, Grand Island, NY) with 15\% knockout serum replacement (Gibco BRL), $10^{3} \mathrm{U}$ leukaemia inhibitory factor (LIF) $\mathrm{ml}^{-1}$ (AMRAD Operations Pty Ltd, Melbourne), 2 mmol L-glutamine $\mathrm{I}^{-1}$ (Gibco $\mathrm{BRL}$ ), $1 \%(\mathrm{v} / \mathrm{v})$ non-essential amino acid solution (Gibco $\mathrm{BRL}$ ) and $55 \mu \mathrm{mol}$ 2-mercaptoethanol $\mathrm{I}^{-1}$ (Wako Pure Chemical Industries, Osaka) for 3 days on a feeder layer derived from fibroblasts of day 15 fetuses. ES cells were synchronized at metaphase with $0.5 \mu \mathrm{g}$ nocodazole $\mathrm{ml}^{-1}$ (Sigma Chemical Co., St Louis, MO) for 2 h. Metaphase- arrested cells were selected and used as donors for oocyte reconstruction.

\section{Embryo manipulation}

The superovulated oocytes from B6CBF1 female mice were collected $14 \mathrm{~h}$ after hCG administration. After enucleation of the metaphase II chromosomes, an ES cell arrested at metaphase was introduced into the perivitelline space of the enucleated oocyte with inactivated Sendai virus (HVJ), which induces fusion within $20 \mathrm{~min}$. Reconstructed embryos were cultured in CZB (Chatot et al., 1990) for $2 \mathrm{~h}$ and activated

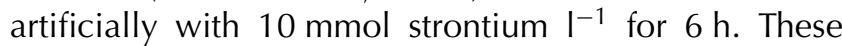
reconstructed embryos were cultured in CZB for 4 days. Control embryos were produced by pronuclear transfer, in which $\mathrm{C} 57 \mathrm{BL} / 6 \mathrm{~N}$ oocytes were fertilized in vitro with spermatozoa from $\mathrm{CBA} / \mathrm{N}$ males and the resultant pronuclei were transferred into enucleated B6CBF1 eggs. Blastocysts derived from in vitro culture were transferred to the uterine horns of ICR female mice on day 2.5 of pseudopregnancy. Four to six blastocysts were transferred to exclude the effect of litter size on fetuses and placentae (Shimozawa et al., 2002a). At days 9.5, 12.5, 17.5 and 19.5 after mating, pregnant mice were killed by cervical dislocation and the fetuses were collected.

\section{Quantitative expression analysis of imprinted genes}

Total RNA was isolated from fetuses at days 9.5, 12.5 and 17.5 after mating and from placentae at days 12.5 and 17.5 after mating with SV Total RNA Isolation System (Promega, Madison, WI). Total RNA was reverse transcribed to cDNA using SUPERSCRIPT II (Gibco BRL). cDNA synthesized from either 0.01 or $0.1 \mu \mathrm{g}$ total RNA was applied to real-time PCR for quantitative expression analysis of $\beta$-actin, which is an internal control gene, eight imprinted genes (Igf2, H19, Igf2r, Air, Mest1/Peg1, Peg3, Nnat and Ndn) and Igf2 PO transcript using LightCycler System (Roche Molecular Biochemicals, Mannheim). The data were obtained from three individual trials for each sample. The primers used for PCR were: $\beta$-actin; $5^{\prime}$-CCTGTATGCCTCTGGTCGTA- $3^{\prime}$ and $5^{\prime}$-CCATCTCCTGCTCGAAGTCT-3'; H19: 5'-CATGTCTGGGCCTTTGAA- ${ }^{\prime}$ and $5^{\prime}$-TTGGCTCCAGGATGATGT-3'; Igf2: 5'-AGGGGAGCTTGTTGACACG-3' and 5'-GGGTATCTGGGGAAGTCGTC-3'; lgf2r: 5'-CGGGCGTGTCCTACAAGTA-3' and 5'-CGGCCTGAGTGAACTTTCAC-3'; Air: 5'-GTGGATTCAGGTTTCATG-3' and 5'-GGCCCAGATATAGAATGT-3'; Peg1: 5'-TCTCCAAAAGCTCCTCAAAG-3' and 5'-ATGAATGGGGATGGACACAG-3'; Peg3: 5'-GAGGAAGGAGAAGATCAAGA-3' and 5'-TTCAATGTAGCCAGAGCACT-3'; Nnat: 5'-AAGCCCTACATCTCGGTGCAGAAG-3' and 5'-TCCCTGTCTCCAGGAGCTTACAATC-3'; and Ndn: 5'-AGGACTAAAAAGGTCCAGGGGCAC- ${ }^{\prime}$ and $5^{\prime}$-CAGTCCATTCCACATGGATGCTTCC$3^{\prime}$. In the case of the Igf2 PO domain, nested PCR was carried out because this gene has a complex region that 
produces multiple transcripts from alternative promoters resulting in sense and anti-sense transcripts (Moore et al., 1997). Primers for first-round PCR were selected to avoid amplification of anti-sense transcripts. The following primers were used: 5'-CTTTGGAGGGGGCTGCTAATA$3^{\prime}$ at P0 and 5'-CGACCCCGGCGGGCACGCAGG- $3^{\prime}$ at E6. PCR amplification was carried out with a HotStarTaq DNA Polymerase (QIAGEN, Hilden). The PCR was performed by an initial denaturation at $95^{\circ} \mathrm{C}$ for $15 \mathrm{~min}$ and 65 cycles of $95^{\circ} \mathrm{C}$ for $1 \mathrm{~min}, 65^{\circ} \mathrm{C}$ for $1 \mathrm{~min}$ and $72^{\circ} \mathrm{C}$ for $2 \mathrm{~min}$. A final period of extension was carried out for $12 \mathrm{~min}$. The PCR products were used for second-round PCR using the LightCycler System. Expression of each gene was evaluated on the basis of the expression of $\beta$ actin for individual samples, and represented a relative percentage of the expression of controls at day 9.5 after mating.

\section{Bisulphite analysis}

Fetuses and extraembryonic tissues at day 9.5 after mating were incubated in $163 \mu$ l lysis solution $(6 \mathrm{~mol}$ guanidine hydrochloride $\mathrm{I}^{-1}(140 \mu \mathrm{l}), 7.5 \mathrm{~mol}$ ammonium acetate $\mathrm{I}^{-1}(10 \mu \mathrm{l}), 20 \%(\mathrm{w} / \mathrm{v})$ sarkosyl $(10 \mu \mathrm{l})$ and $10 \mathrm{mg}$ proteinase $\left.\mathrm{K} \mathrm{ml}^{-1}(3 \mu \mathrm{l})\right)$ at $55-60^{\circ} \mathrm{C}$ for $2 \mathrm{~h}$. The isolated DNA was treated with sodium bisulphite using a CpGenome DNA Modification kit (INTERGEN, Purchase, NY). The bisulphite-modified DNA was amplified by PCR. The methylated status of H19 DMR was examined using the following primers: Bis5F: 5'-TTTGGGTAGTTTTTTTTAGTT-3'; Bis4R1: 5'-TCCTAATCTCTAATCTCAAC-3'; and Bis4R2: 5'-AACCCCAACCTCTACTTTTA-3'. For first-round PCR, the primers Bis5F and Bis4R1 were used; and for second-round PCR, the primers Bis5F and Bis4R2 were used. PCR amplification was carried out with an Advantage cDNA PCR kit (Clontech, Palo Alto, CL) in $20 \mu \mathrm{l}$ volumes using GeneAmp PCR System 9700 (Applied Biosystems, Foster City, CL). First-round PCR was performed by an initial denaturation at $94^{\circ} \mathrm{C}$ for $4.5 \mathrm{~min}$ and 35 cycles of $94^{\circ} \mathrm{C}$ for $30 \mathrm{~s}, 52^{\circ} \mathrm{C}$ for $30 \mathrm{~s}$ and $72^{\circ} \mathrm{C}$ for $1 \mathrm{~min}$. A final period of extension was carried out for $6 \mathrm{~min}$. One microlitre of 100-1000-fold diluted first-round PCR product was used for second-round PCR. The cycling condition for the second-round PCR was the same as for the first-round PCR. The methylated status of $\lg f 2 r$ DMR2 was examined using the following primers: $13 \mathrm{~B}-1$ : 5'-AATCCTCCCCTTATACAATTTACA-3' and 13B-4: 5'TAGAGGATTTTAGTATAATTTTAA-3'. PCR amplification was carried out with a HotStarTaq DNA Polymerase (QIAGEN). PCR was performed by an initial denaturation at $95^{\circ} \mathrm{C}$ for $15 \mathrm{~min}$ and 65 cycles of $95^{\circ} \mathrm{C}$ for $30 \mathrm{~s}$, $56^{\circ} \mathrm{C}$ for $30 \mathrm{~s}$ and $72^{\circ} \mathrm{C}$ for $30 \mathrm{~s}$. A final period of extension was carried out for $5.5 \mathrm{~min}$. The PCR products were ligated into pGEM-T Easy Vector (Promega), cloned and sequenced on ABI PRISM Model 3700 (Applied Biosystems) or Long-Read Tower (Amersham Pharmacia
Biotech, Tokyo). In this methylation analysis, fetuses from mating were used as controls.

\section{Statistical analysis}

The difference of the weight of the fetus and placenta and gene expression between controls and clones were analysed using ANOVA and $t$ test by StatView (SAS Institute Inc., Cary, NC); $P$ values $<0.05$ were considered significantly different.

\section{Results}

\section{ES cloned fetuses and placentae}

The present study used a targeted ES cell line known to result in overgrowth of fetuses and placentae when used as donor cells for embryo cloning (Shimozawa et al., 2002a). However, the developmental ability of this targeted ES cell is not significant in comparison with non-targeted ES cells, as the productive rate of ES cloned mice from this ES cell is relatively high (Shimozawa et al., 2002b). The fetuses from ES clones were heavier than fetuses from controls with significant differences at days 17.5 and 19.5 after mating $(P<0.05)$ (Fig. $1 \mathrm{a}-\mathrm{C})$. The placental mass of controls at day 12.5 after mating was $0.1 \pm 0.01 \mathrm{~g}(n=5)$, which was about $70 \%$ of the final size at term. In contrast, the ES cloned placentae showed excessive growth between day 12.5 and day 17.5 after mating, reaching $0.54 \pm 0.11 \mathrm{~g}(n=5)$, almost fourfold the mass of the controls (Fig. 1a,b,d).

\section{Expression of imprinted genes in ES cloned fetuses and placentae}

The expression of imprinted genes in the fetuses at days $9.5,12.5$ and 17.5 after mating and the placentae at days 12.5 and 17.5 after mating was evaluated quantitatively by real-time PCR and represented as relative levels to the level of the expression of controls at day 9.5 after mating (Fig. 2a). The genes were classified into four groups on the basis of their normal expression in developing control fetuses: (i) gene expression is maintained during development (Igf2r and Peg3); (ii) gene expression decreases with development (Air and Peg1/Mest); (iii) gene expression increases with development (H19 and $\mathrm{Ndn}$ ); and (iv) gene expression is at its peak at day 12.5 after mating (Igf2 and Nant).

In the day 9.5 cloned fetuses that were examined, the expression of lgf 2 was $20 \%$ of that of the controls. The other genes were expressed at the same levels as the controls. In one of the three clones, extremely low expression was evident in all genes examined except for the $\mathrm{H} 19$ gene, indicating that it could not survive long beyond this stage. In day 12.5 cloned fetuses that were examined, three genes closely related to fetal growth, Igf2, Igf $2 r$ and Peg3, were expressed at significantly lower amounts except Igf2 $r$, whereas the other genes 
(a)

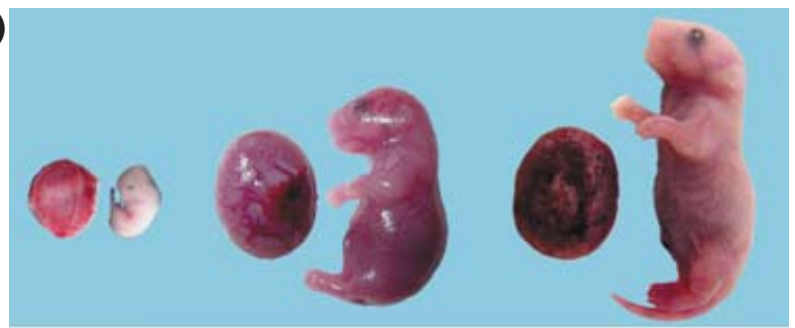

(b)

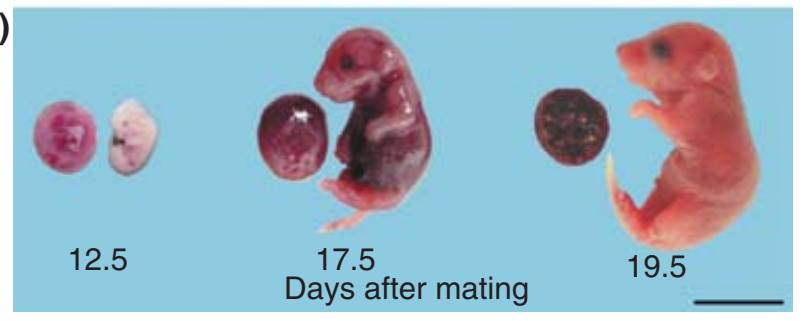

(c)

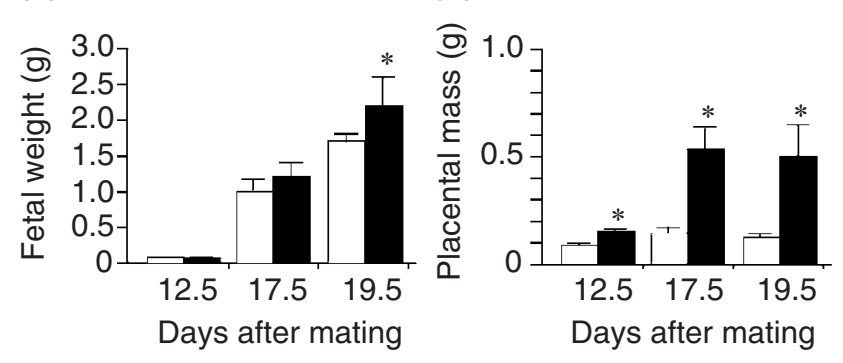

Fig. 1. Development of (a) embryonic stem cell-cloned and (b) control mouse fetuses and placentae at days 12.5, 17.5 and 19.5 after mating. (c) The weight of fetuses and (d) the mass of placentae in controls $(\square)$ and embryonic stem clones $(\boldsymbol{\square})$ are expressed as means \pm SE. ${ }^{*}$ Significantly different from controls $(P<0.01)$. Scale bar represents $1 \mathrm{~cm}$.

were expressed at amounts similar to those of controls. Throughout development of the fetus, $\mathrm{H} 19$ was expressed at increasing abundance in controls. However, in the cloned fetuses, the expression of this gene was greatly diminished as development progressed. The expression of other genes in the clones at day 17.5 after mating was not significantly different from that of the controls, with the exception of Air, an anti-sense mRNA of Igf2r.

Expression of some imprinted genes in the placentae was different from those in the fetuses (Fig. 2b). Although, Air, Peg1/Mest and Nnat genes were expressed at low levels at day 12.5 after mating, the expression of eight imprinted genes was not different from controls. At day 17.5 after mating, $\mathrm{H} 19$ and Igf2 were expressed at significantly low levels, and Peg1/Mest expression was significantly higher in cloned placentae. The transcription of the $P O$ domain of the lgf2 gene, which is a transcript of the promoter domain of the lgf2 gene was expressed only in the placenta from the paternal allele (Moore et al., 1997). The expression of $P O$ in the placentae of the clones was more than fourfold that in controls at day 12.5 after mating.

\section{DMR methylation pattern in $\mathrm{H} 19$ and Igf2r}

Monoallelic expression of imprinted genes is regulated by the methylated status of CpG sites in the DMR of each gene. The methylation status of DMR regions of the $\mathrm{H} 19$ and Igf2r genes, which are imprinted and expressed solely from the maternal allele, in five cloned fetuses and the extraembryonic tissues at day 9.5 after mating were assessed (Fig. 3). In clone 21, the fetus was not turned, with no heartbeat and developmental retardation; in clone 8 , the fetus was not turned, with heartbeat and developmental retardation; in clone 13, the fetus was turned, with no heartbeat and developmental retardation; and in clones 23 and 24, the fetuses were turned, with heartbeat and normal phenotype.

In control fetuses and the extraembryonic tissues, both hyper- and hypomethylated alleles in the DMR of the H19 gene were detected, which could be interpreted as paternal and maternal alleles, respectively (Fig. 4a). The methylation status was divided into two patterns in the cloned fetuses and the extraembryonic tissues. Both hyper- and hypomethylated alleles of the DMR were detected in clones 8 and 21, which were retarded and not turned at recovery. In contrast, only the hypermethylated allele of the DMR was detected in clones 13, 23 and 24 , which were turned at recovery. The methylation status of the DMR in the extraembryonic tissues was similar to those of the fetus. The donor ES cells (TT2 line) were analysed to compare the methylation status with that of cloned fetuses. The data showed that the ES cells contain both hyper- and hypomethylated alleles with three predominantly methylated $(3375,3462$ and 3580) and unmethylated (3302, 3384 and 3563) CpG sites, respectively.

Methylation analysis of the Igf2 $r$ gene detected both hyper- and hypomethylated alleles of DMR2 in controls and also in cloned fetuses 13, 23 and 24, although the hypermethylated allele was dominant in clone 13 (Fig. 4b). In contrast, cloned fetuses 8 and 21 contained only unmethylated alleles except in the one DNA clone in fetus 8 . In the extraembryonic tissues, both hyperand hypomethylated alleles were detected except in the one case, clone 21, in which the DMR2 was completely unmethylated. In the ES cells, both hyperand hypomethylated alleles of the DMR2 were detected except for one CpG site (site no. 1002), which was completely methylated.

\section{Discussion}

Studies to date have determined that ES and somatic cloned animals display overgrowth of the fetus and placenta (Wakayama and Yanagimachi, 1999; Eggan et al., 2001; Ono et al., 2001a). The present study produced ES cloned fetuses using the ES cell line that is known to result in overgrowth of the fetus and placenta when used in cloning (Shimozawa et al., 2002a). The expression of 
(a)
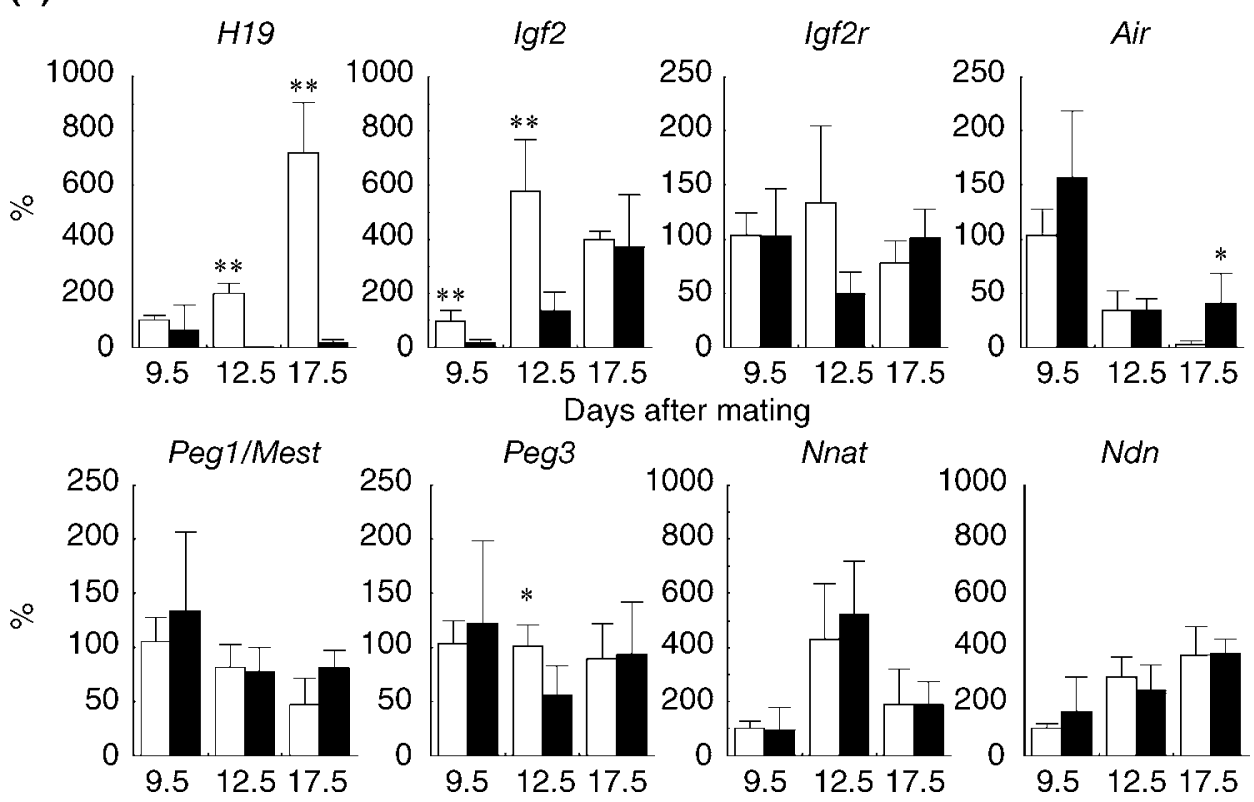

(b)

Days after mating
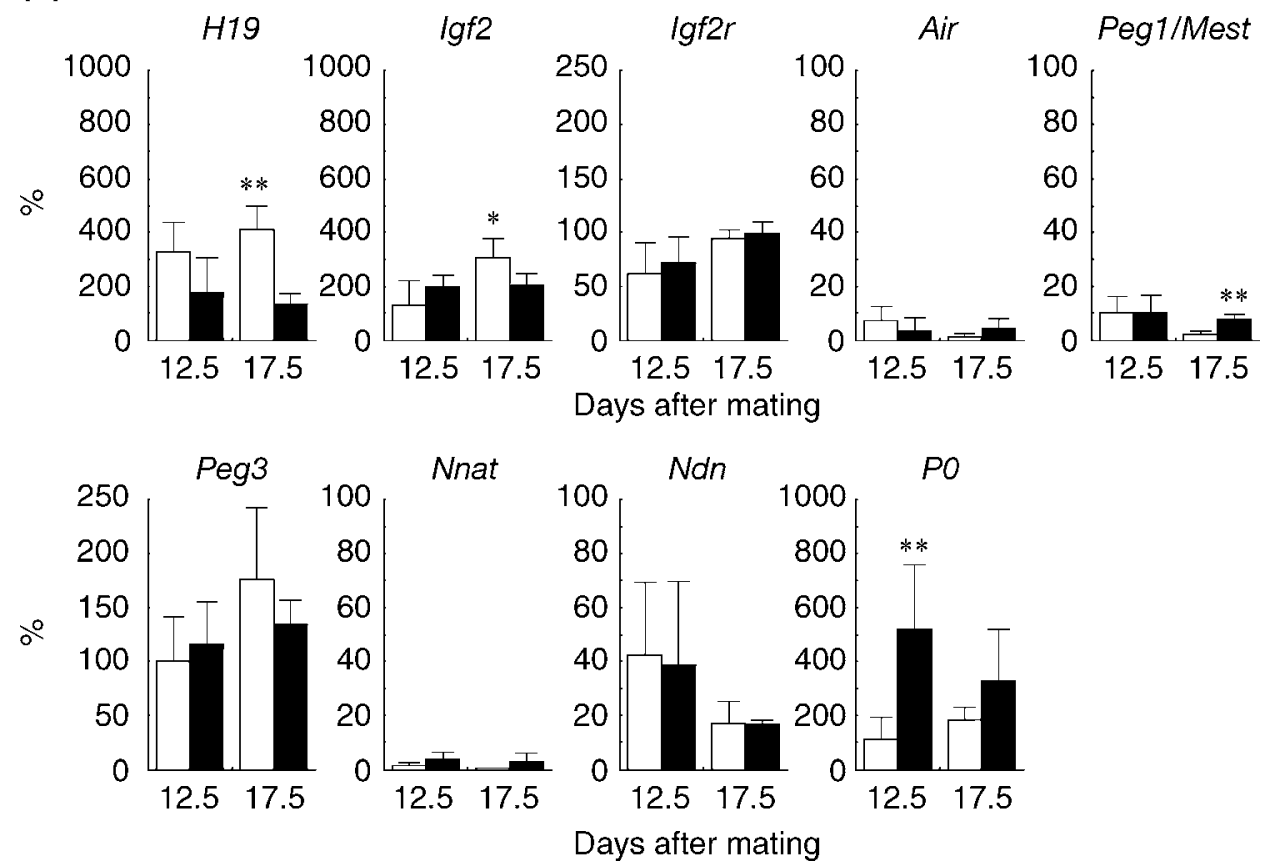

Fig. 2. Quantitative analysis of imprinted gene expression from (a) fetuses and (b) placentae of control $(\square)$ and embryonic stem cloned mice $(\boldsymbol{\square})$ by real-time PCR. The mean expression was calculated as a percentage of the expression of controls at day 9.5 after mating. Standard errors of means are indicated by bars. Asterisks denote significant difference from the control $\left({ }^{*} P<0.05\right.$ and $\left.{ }^{* *} P<0.01\right)$.

imprinted genes was examined at early (day 9.5 after mating), mid- (day 12.5 after mating) and late (day 17.5 after mating) gestation to clarify such developmental abnormalities. As expected, these cloned fetuses were $30 \%$ heavier than controls at day 17.5 and day 19.5 after mating. Furthermore, the associated placentae were remarkably increased between day 12.5 and day 17.5 after mating and were four times heavier than those of controls. This finding is unusual as the mass of placentae at day 12.5 after mating was up to $80 \%$ of the final size at day 17.5 after mating in controls.

Eight imprinted genes were analysed quantitatively to understand mechanisms underlying the overgrowth of fetuses and placentae. The results showed that the H19 gene was completely repressed through development in cloned fetuses and the placentae. Mouse H19 and 

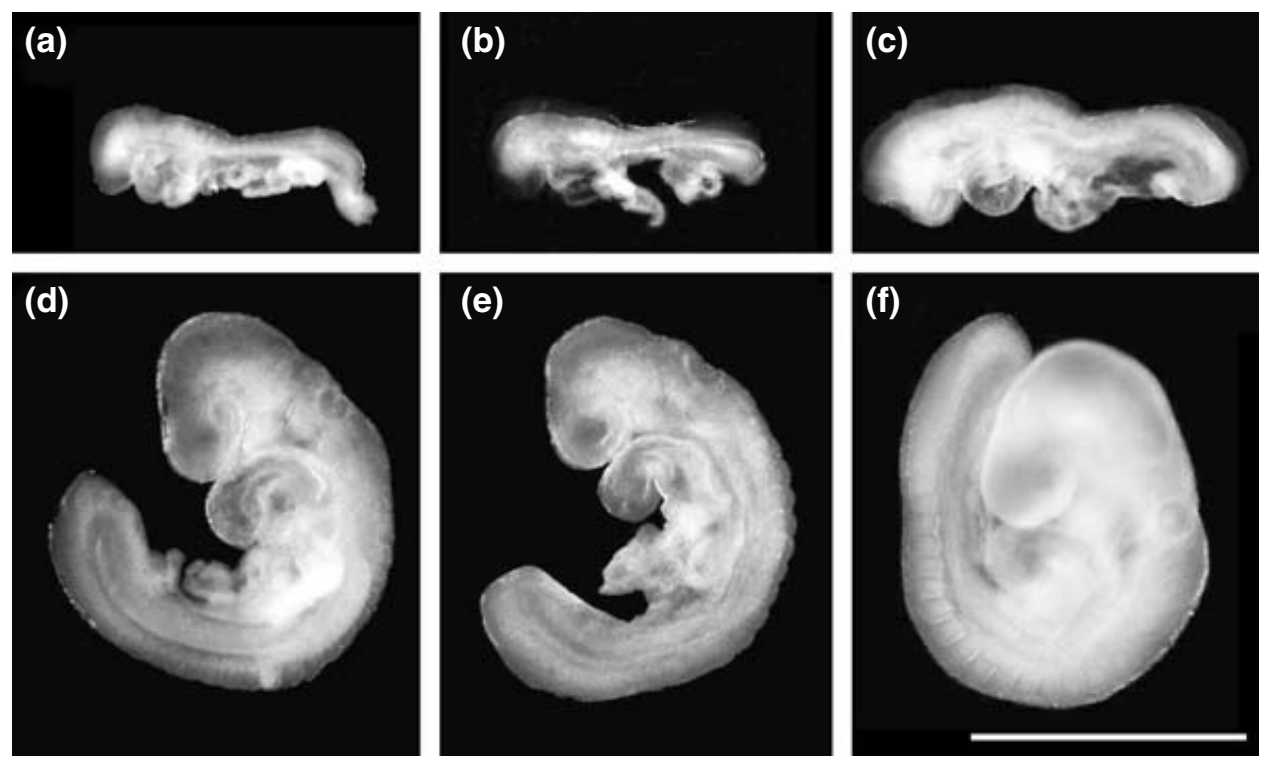

Fig. 3. Morphology of (a-e) embryonic stem (ES) cloned and (f) control mouse fetuses at day 9.5 after mating, which were used for DNA methylation analysis. The nature of each ES-cloned fetus numbered (a) 21, (b) 8, (c) 13, (d) 23 and (e) 24 is described in the text. Scale bar represents $1 \mathrm{~mm}$.

Igf2 genes, which are located on the distal portion of chromosome 7 (Caspary et al., 1998), exhibit reciprocal expression by the parental allele. When one of these genes is transcribed, another gene is silenced. Humphreys et al. (2001) reported that the H19 gene expression was repressed in the ES cloned pups in which the DMR was hypermethylated and expression of the Igf2 gene was increased. Unexpectedly, the depleted expression of $\mathrm{H} 19$ was not associated with an increase of Igf2 expression in cloned fetuses at day 9.5 and day 12.5 after mating. Thus, transcription of the Igf2 gene in the ES cloned fetuses at day 9.5 and day 12.5 after mating may be downregulated. Thus, the enhancer competition model between the Igf2 and H19 genes, in which these two genes compete for the shared enhancer elements located downstream of H19, may be disrupted. Furthermore, the $\lg f 2 r$ gene, which is maternally expressed and interferes with the mitogenic effect of Igf2, was expressed at half the amount of the controls at day 12.5 after mating. The expression of Air, the anti-sense mRNA of Igf2 $r$, which could affect the function of the Igf2r gene (Lyle et al., 2000), in clones did not significantly differ from that in controls at days 9.5 and 12.5 after mating; however, Air was still expressed by day 17.5 after mating in clones, after it had disappeared from controls. These results indicate that lower expression of the Igf2 $r$ gene with expression of the Air at day 17.5 after mating clones can induce overgrowth of the fetus in the late stage of gestation.

Gene expression in the placenta was also analysed to obtain further insight into the overgrowth phenomena. The expression of the H19 and Igf2 genes was reduced at day 17.5 after mating in cloned placentae. This expression is not inconsistent with the present theory for the regulation of the two genes. Expression of the $\operatorname{lgf} 2 r$ gene in the placenta in clones appeared the same as in controls. From these results, it is difficult to deduce a clear reason for the overgrowth in the clones. The expression of the $P O$ domain of Igf2, which contains the coding exons 4-6, and expresses specifically from the placenta (Moore et al., 1997) with predominant expression in the labyrinthine trophoblast cells, was examined (Constancia et al., 2002). The absence of the $P O$ transcript in a gene deletion experiment resulted in deficiency in growth of the placenta and reduction in permeability for nutrients and led to $69 \%$ of normal birth weight (Constancia et al., 2002). In the present study, the $P O$ transcript in the placenta of clones was expressed at four times the amount expressed in controls at day 12.5 after mating, indicating that the overexpression of the Igf2 $P 0$ transcript is responsible for the placental overgrowth. This overexpression may lead to fetal overgrowth. Furthermore, considering the placental hypertrophy of the cloned fetuses, the $P O$ transcript from the placenta could be concerned in the overgrowth of the fetus.

Although the mechanism for aberrant expression of some imprinted genes in the cloned fetus is unclear, several factors including histone acetylation and DNA methylation may be involved (Bird and Wolffe, 1999; Reik et al., 2001). Studies so far have shown that DNA methylation status differs between fertilized and cloned embryos in cattle (Kang et al., 2001a). The present study analysed DNA methylation of the H19 DMR and Igf2r DMR2 in the fetuses at day 9.5 after mating, and found that methylation status differed depending on phenotype. 
(a)

Fetus

Extraembryonic tissue

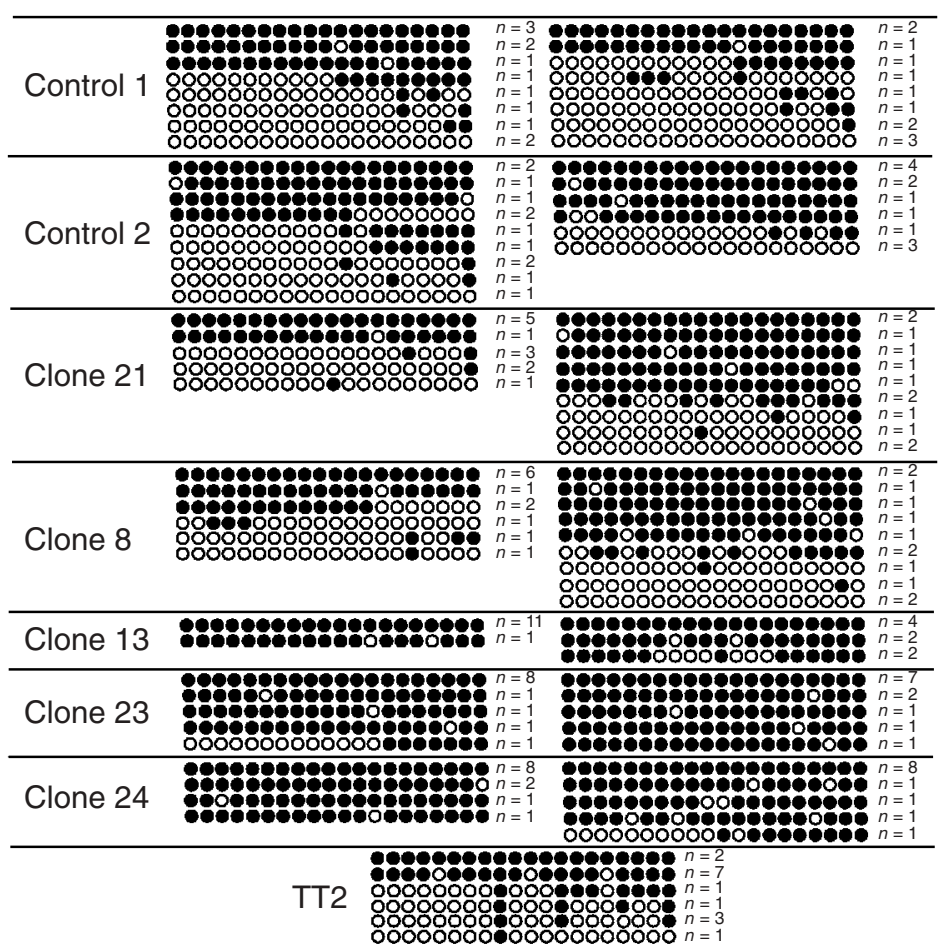

(b)

Fetus

Extraembryonic tissue

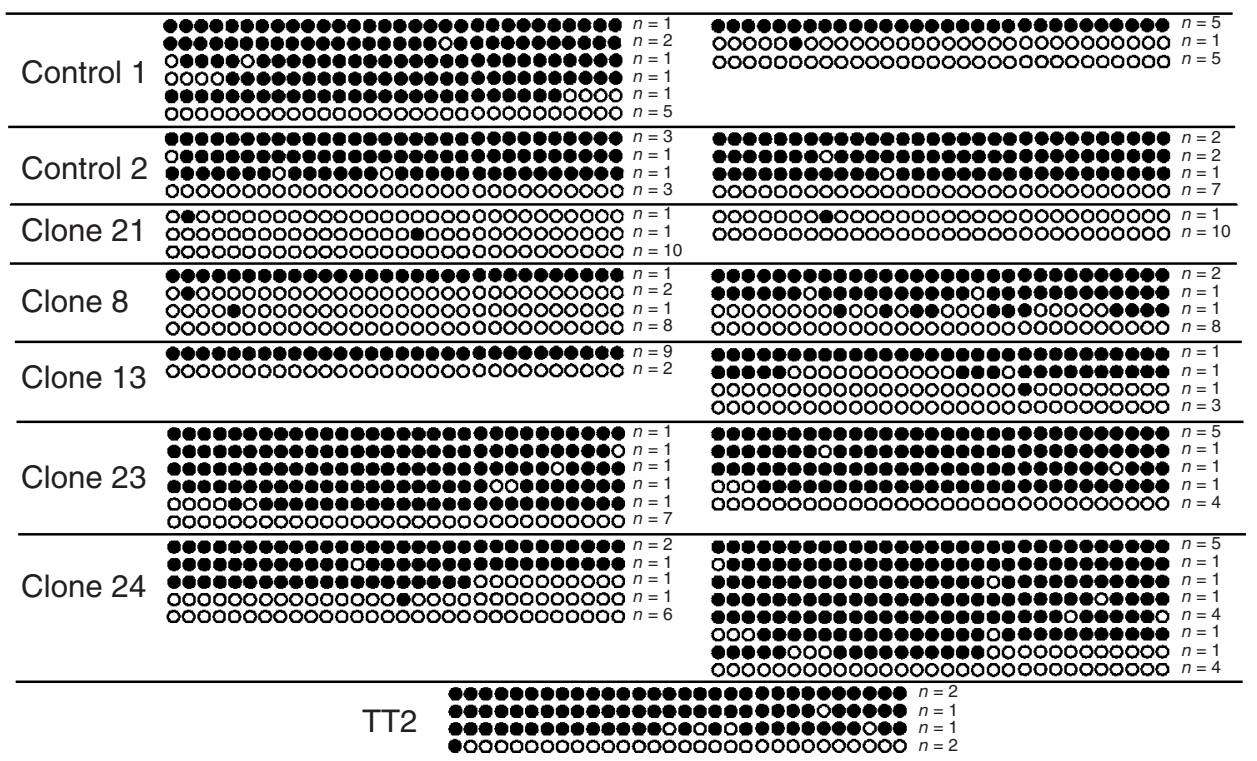

Fig. 4. (a) Methylation patterns in differently methylated region (DMR) of the mouse $\mathrm{H} 19$ gene (GenBank accession number AF049091); analysed region is from 3248 to 3615 of the gene containing $20 \mathrm{CpG}$ sites. A filled and open circle corresponds to methylated $\mathrm{CpG}$ and unmethylated CpG sites, respectively. (b) Methylation patterns in DMR2 of the Igf2r gene (GenBank accession number; L06446); analysed region is from 964 to 1413 of the gene containing 30 CpG sites. $n$ : number of DNA clones. 
In the apparently normal-looking fetuses, H19 DMR was completely methylated (that is, not normal), but in the retarded fetuses, both methylated and hypomethylated DNA clones were observed (as expected in the normal situation). This finding supports the results of the present study on gene expression analysis and leads to the idea that the hypermethylated H19 DMR causes complete repression of the gene throughout development. On the contrary, in the Igf2r DMR2, all DNA clones except for one were apparently unmethylated in the developmentally retarded fetuses, indicating that this unmethylated status may be the result of overexpression of Igf2 $r$, and may be one of the reasons for abnormal development in cloned embryos.

The methylation status of cytosine residue is not stable in specific genes when cells are cultured in vitro (Doherty et al., 2000). Sasaki et al. (1995) showed that preimplantation mouse embryos cultured in vitro led to biallelic $\mathrm{H} 19$ expression in the extraembryonic tissues.

The ES cells used in the present study as donor nuclei for nuclear transfer maintained the methylated and unmethylated alleles of H19 DMR; however, three each of the 20 CpG sites examined, three were apparently hypermethylated and three were apparently hypomethylated. Comparing the methylation status of controls with that of cloned fetuses shows that methylation of $\mathrm{CpG}$ sites changes some time after embryo reconstruction. The expression of imprinted genes and methylated status were also different between ES cell lines and among subclones (Humpherys et al., 2001). The expression of imprinted genes was affected not only by the culture condition of donor cells, but also by nuclear transfer and subsequent embryo culture (Doherty et al., 2000; Khosla et al., 2001; Young et al., 2001). However, how and when DNA methylation status of donor cells is modified in the cloned embryos is still unclear. The findings from the present study indicate that aberrant expression of the imprinted genes is correlated with altered methylation status, which perhaps influences the developmental ability of ES cloned embryos. It may be valuable to determine the superior epigenetic modifications for donor cells and to establish a procedure for selecting and sorting them to produce cloned animals efficiently.

This work was supported by grants from the Ministry of Education, Science, Culture and Sports of Japan, the Ministry of Agriculture of Japan, the Japanese Society for Promotion of Science and Mecrogen Inc. (Korea).

\section{References}

Baguisi A, Behboodi E, Melican DT et al. (1999) Production of goats by somatic cell nuclear transfer Nature Biotechnology 17 456-461

Bird AP and Wolffe AP (1999) Methylation-induced repression-belts, braces, and chromatin Cell 99 451-454

Caspary T, Cleary MA, Baker CC, Guan XJ and Tilghman SM (1998) Multiple mechanisms regulate imprinting of the mouse distal chromosome 7 gene cluster Molecular and Cellular Biology 18 3466-3474

Chatot CL, Lewis JL, Torres I and Ziomek CA (1990) Development of 1cell embryos from different strains of mice in CZB medium Biology of Reproduction 42 432-440

Chesne P, Adenot PG, Viglietta C, Baratte M, Boulanger L and Renard JP (2002) Cloned rabbits produced by nuclear transfer from adult somatic cells Nature Biotechnology 20 366-369

Constancia M, Hemberger M, Hughes J et al. (2002) Placental-specific IGF-II is a major modulator of placental and fetal growth Nature $\mathbf{4 1 7}$ 945-948

Doherty AS, Mann MR, Tremblay KD, Bartolomei MS and Schultz RM (2000) Differential effects of culture on imprinted H19 expression in the preimplantation mouse embryo Biology of Reproduction 62 1526-1535

Eggan K, Akutsu H, Loring J, Jackson-Grusby L, Klemm M, Rideout WM, Yanagimachi R and Jaenisch R (2001) Hybrid vigor, fetal overgrowth, and viability of mice derived by nuclear cloning and tetraploid embryo complementation Proceedings National Academy of Science USA 98 6209-6214

Humpherys D, Eggan K, Akutsu H, Hochedlinger K, Rideout WM, Biniszkiewicz D, Yanagimachi R and Jaenisch R (2001) Epigenetic instability in ES cells and cloned mice Science 293 95-97

Inoue K, Kohda T, Lee J, Ogonuki N, Mochida K, Noguchi Y, Tanemura K, Kaneko-Ishino T, Ishino F and Ogura A (2002) Faithful expression of imprinted genes in cloned mice Science 295297

Jaenisch R, Eggan K, Humpherys D, Rideout W and Hochedlinger K (2002) Nuclear cloning, stem cells, and genomic reprogramming Cloning and Stem Cells 4 389-396

Kang YK, Koo DB, Park JS, Choi YH, Chung AS, Lee KK and Han YM (2001a) Aberrant methylation of donor genome in cloned bovine embryos Nature Genetics 28 173-177

Kang YK, Koo DB, Park JS, Choi YH, Kim HN, Chang WK, Lee KK and Han YM (2001b) Typical demethylation events in cloned pig embryos - Clues on species-specific differences in epigenetic reprogramming of a cloned donor genome Journal of Biological Chemistry 27639 980-39 984

Kang YK, Koo DB, Park JS, Choi YH, Lee KK and Han YM (2001c) Influence of oocyte nuclei on demethylation of donor genome in cloned bovine embryos FEBS Letters 499 55-58

Kato Y, Tani T, Sotomaru Y, Kurokawa K, Kato J, Doguchi H, Yasue $H$ and Tsunoda Y (1998) Eight calves cloned from somatic cells of a single adult Science 282 2095-2098

Khosla S, Dean W, Brown D, Reik W and Feil R (2001) Culture of preimplantation mouse embryos affects fetal development and the expression of imprinted genes Biology of Reproduction 64 918-926

Lyle R, Watanabe D, te Vruchte D, Lerchner W, Smrzka OW, Wutz A, Schageman J, Hahner L, Davies C and Barlow DP (2000) The imprinted antisense RNA at the Igf2r locus overlaps but does not imprint Mas1 Nature Genetics 25 19-21

Moore T, Constancia M, Zubair M, Bailleul B, Feil R, Sasaki H and Reik W (1997) Multiple imprinted sense and antisense transcripts, differential methylation and tandem repeats in a putative imprinting control region upstream of mouse lgf2 Proceedings National Academy of Science USA 9412 509-12 514

Ogonuki N, Inoue K, Yamamoto Y et al. (2002) Early death of mice cloned from somatic cells Nature Genetics 30 253-254

Onishi A, Iwamoto M, Akita T, Mikawa S, Takeda K, Awata T, Hanada H and Perry AC (2000) Pig cloning by microinjection of fetal fibroblast nuclei Science 289 1188-1190

Ono Y, Shimozawa N, Ito M and Kono T (2001a) Cloned mice from fetal fibroblast cells arrested at metaphase by a serial nuclear transfer Biology of Reproduction 64 44-50

Ono $Y$, Shimozawa N, Muguruma K, Kimoto S, Hioki K, Tachibana M, Shinkai Y, Ito M and Kono T (2001b) Production of cloned mice from embryonic stem cells arrested at metaphase Reproduction 122 731-736

Reik W, Dean W and Walter J (2001) Epigenetic reprogramming in mammalian development Science 293 1089-1093

Renard JP, Chastant S, Chesne P, Richard C, Marchal J, Cordonnier N, Chavatte $\mathbf{P}$ and Vignon X (1999) Lymphoid hypoplasia and somatic cloning Lancet 353 1489-1491 
Rideout WM, Eggan K and Jaenisch R (2001) Nuclear cloning and epigenetic reprogramming of the genome Science 293 1093-1098

Sasaki H, Ferguson-Smith AC, Shum AS, Barton SC and Surani MA (1995) Temporal and spatial regulation of $\mathrm{H} 19$ imprinting in normal and uniparental mouse embryos Development 121 4195-4202

Shimozawa N, Ono Y, Kimoto S, Hioki K, Araki Y, Shinkai Y, Kono T and Ito $\mathbf{M}$ (2002a) Abnormalities in cloned mice are not transmitted to the progeny Genesis 34 203-207

Shimozawa N, Ono Y, Muguruma K, Hioki K, Arai Y, Shinkai Y, Kono T and Ito $\mathbf{M}$ (2002b) Direct production of gene-targeted mice from ES cells by nuclear transfer and gene transmission to their progeny Experimental Animals 51 375-381

Shin T, Kraemer D, Pryor J, Liu L, Rugila J, Howe L, Buck S, Murphy K, Lyons L and Westhusin M (2002) Cell biology: a cat cloned by nuclear transplantation Nature $\mathbf{4 1 5} 859$

Wakayama T and Yanagimachi R (1999) Cloning of male mice from adult tail-tip cells Nature Genetics 22 127-128

Wakayama T, Perry AC, Zuccotti M, Johnson KR and Yanagimachi R (1998) Full-term development of mice from enucleated oocytes injected with cumulus cell nuclei Nature 394 369-374
Wells DN, Misica PM and Tervit HR (1999) Production of cloned calves following nuclear transfer with cultured adult mural granulosa cells Biology of Reproduction 60 996-1005

Wilmut I, Schnieke AE, McWhir J, Kind AJ and Campbell KH (1997) Viable offspring derived from fetal and adult mammalian cells Nature 385 810-813

Xue F, Tian XC, Du F, Kubota C, Taneja M, Dinnyes A, Dai Y, Levine $\mathbf{H}$, Pereira LV and Yang $\mathbf{X}$ (2002) Aberrant patterns of $X$ chromosome inactivation in bovine clones Nature Genetics 31 216-220

Young LE, Fernandes K, McEvoy TG, Butterwith SC, Gutierrez CG, Carolan C, Broadbent PJ, Robinson JJ, Wilmut I and Sinclair KD (2001) Epigenetic change in IGF2R is associated with fetal overgrowth after sheep embryo culture Nature Genetics 27 153-154

Received 10 April 2003

First decision 21 May 2003

Revised manuscript received 23 June 2003.

Accepted 4 July 2003. 